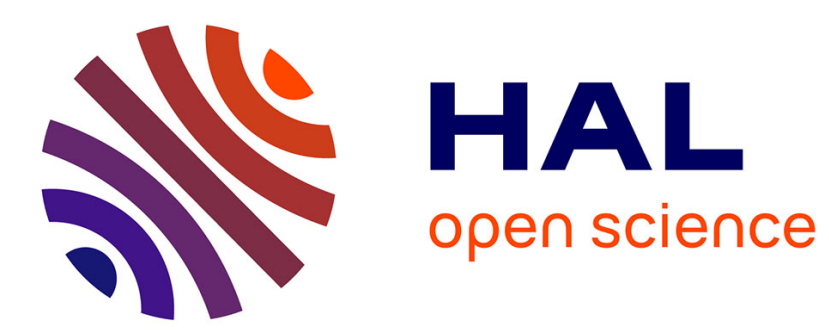

\title{
A matching model of the market for migrant smuggling services
}

\author{
Claire Naiditch, Radu Vranceanu
}

\section{To cite this version:}

Claire Naiditch, Radu Vranceanu. A matching model of the market for migrant smuggling services. 2020. hal-02463193

\section{HAL Id: hal-02463193 \\ https://essec.hal.science/hal-02463193}

Preprint submitted on 31 Jan 2020

HAL is a multi-disciplinary open access archive for the deposit and dissemination of scientific research documents, whether they are published or not. The documents may come from teaching and research institutions in France or abroad, or from public or private research centers.
L'archive ouverte pluridisciplinaire HAL, est destinée au dépôt et à la diffusion de documents scientifiques de niveau recherche, publiés ou non, émanant des établissements d'enseignement et de recherche français ou étrangers, des laboratoires publics ou privés. 


\section{ESSEC \\ BUSINESS SCHOOL}

\section{A MATCHING MODEL OF THE MARKET FOR MIGRANT SMUGGLING SERVICES}

CLAIRE NAIDITCH, RADU VRANCEANU

ESSEC RESEARCH CENTER

WORKING PAPER 2002

JANUARY 30, 2020 
January 10, 2020

\title{
A matching model of the market for migrant smuggling services
}

\section{Claire Naiditch* and Radu Vranceanu ${ }^{\dagger}$}

\begin{abstract}
The important flows of irregular migration could not exist without the emergence of a criminal market for smuggling services. A matching model à la Pissarides (2000) provides a well-suited framework to analyze such a flow market with significant trade frictions. Our analysis considers the competitive segment of this underground market in which small-business smugglers can freely enter. The model allows us to determine the equilibrium number of smugglers, the matching probability, the number of successful irregular migrants and, as an original concept, the equilibrium migrant welfare. Changes in parameters can be related to the various policies implemented by destination countries to cut down irregular migration.
\end{abstract}

JEL Classification Index: F22, O15, J46.

Keywords: Smuggling, Irregular migration, Matching model, Migrant welfare.

*LEM-CNRS (UMR 9221), University of Lille, Cité Scientifique, 59655 Villeneuve d'Ascq Cedex, France, E-mail: claire.naiditch@univ-lille.fr

${ }^{\dagger}$ ESSEC Business School and THEMA. 1 Av. Bernard Hirsch, 950210 Cergy. Mail: vranceanu@essec.edu 


\section{Introduction}

In the last few years, migratory flows from developing to developed countries have intensified; populations in several developing countries were exposed to major distress due to wars, ethnical conflicts, and economic difficulties driven by internal factors (poor economic policies, corruption, deteriorating terms of trade) or external factors such as climate change. On the other hand, with a few exceptions, developed countries did little to improve their migrant absorption capacity, despite a declining population. In this context, irregular migratory flows became a substantial component of total migratory flows (Ambrosini, 2016; Vespe et al., 2017; Naiditch and Vranceanu, 2017).

In turn, these massive flows of irregular migration led to the development of a new black market for migrant smuggling services. The UN Protocol Against the Smuggling of Migrants (2000) defines migrant smuggling as "the procurement, in order to obtain, directly or indirectly, a financial or other material benefit, of the illegal entry of a person into a State Party of which the person is not a national or a permanent resident". ${ }^{1}$ Smuggling is the profit-making business of illegally carrying migrants across borders; contrary to trafficking, it does not require an element of exploitation, coercion, or violation of human rights (IOM, 2019). Salt and Stein (1997) were the first to describe in a systematic way the successive stages of smuggling, and the complex nature of the smuggling activities. Smugglers would provide migrants with the logistics for their long and risky journey, including planning (based on their knowledge of the routes and risks), minimal shelter and food, means of transports, fake documents, would assure their protection against robbery and other crimes, sometimes would bribe officials to close their eyes when they cross the controls.

Data on irregular migration, smuggling, and human trafficking are by definition extremely

\footnotetext{
1 Art. 3(a), UN Protocol Against the Smuggling of Migrants by Land, Sea and Air, supplementing the United Nations Convention against Transnational Organized Crime, 2000.
} 
difficult to gather. An influential Europol report (Europol, 2016), drafted immediately after the 2015 peak in irregular migration to the EU from poor and war areas in the Middle East and in the Horn of Africa, documents that more than $90 \%$ of the incoming migrants were facilitated by criminal networks, whose turnover in 2015 could have totaled between 3 and 6 billion euros. One can read from the website of the United Nations Office on Drugs and Crime (UNODC) that:

"Criminals are increasingly providing smuggling services to irregular migrants to evade national border controls, migration regulations and visa requirements. Most irregular migrants resort to the assistance of profit-seeking smugglers. As border controls have improved, migrants are deterred from attempting to illegally cross them themselves and are diverted into the hands of smugglers." ${ }^{2}$

According to the UNODC, there is evidence that, at a minimum, 2.5 million migrants were smuggled worldwide, for an economic return of US\$ 5.5-7 billion in 2016 (UNODC, 2018). ${ }^{3}$ More recently, Frontex interviewed newly arrived migrants in the Mediterranean area and found that $84 \%$ of the migrants interviewed used smugglers services, while only $7 \%$ of them arrived in Europe without the help of smugglers (Frontex, 2019: 28).

Given the substantial consequences of irregular migration, it goes beyond a say that scholars should understand and provide explanations about the organization of the market for smuggling services. In this paper, we analyze the market for migrant smuggling services in a modern matching framework that acknowledges the substantial trade frictions specific to this environment. In particular, we study the effect of policies intended to curb irregular migration on the number of smugglers and the level of the smuggling fee, as well as on the

\footnotetext{
${ }^{2}$ As accessed on 26/05/2019:

www.unodc.org/unodc/en/ human-trafficking/migrant-smuggling-a-deadly-business.html

${ }^{3}$ See also the country-specific analyses by McAuliffe and Laczko (2016).
} 
number of irregular migrants and the intertemporal utility of migrants.

Despite the documented importance of the smugglers as facilitators of irregular migration, theoretical investigations of this activity are relatively scarce. Gathman (2008) introduces a cost/benefit analysis to explain smugglers' choice of the crossing border point. Djajic and Vinogradova (2019) use a dynamic, intertemporal cost/benefit analysis to determine the migration strategy of a low-skilled worker who can choose between legal temporary migration and long term irregular migration. Several papers have analyzed the financial relationship between migrants and the criminal smuggling organization as a provider of transport services as well as financial resources. Building on the assumptions that many candidates to migration do not have the funds to pay for the smuggling fee, they study the debt contract between the migrant and the criminal organization, which in many cases involves migrant exploitation once he/she reaches the destination, and, in some cases, leads the migrant to default on his/her "obligations" (Friebel and Guriev, 2006; Tamura, 2010, 2013; Djajic and Vinogradova, 2014).

The UNODC (2018: 6) uses a traditional supply and demand setting to analyze the market for migrants smuggling. On the supply side, the UN report indicates that "smugglers advertise their business where migrants can be easily reached, such as in neighborhoods home to diaspora communities, in refugee camps or in various social networks online". They explain that migrants demand for smuggling services is "determined by socio-economic conditions, family reunification as well as persecution, instability or lack of safety in origin countries". Similar to any market, the smuggling market involves a price paid by migrants to smugglers for their service, the smuggling fee. Petros (2005) reports that smuggling fees depend on the distance travelled, the mode of transport, the number and characteristics of people being moved, and of circumstantial conditions. Studying the smuggling market to Europe in the 
mid 2010, Abdel Aziz et al. (2015: 28) emphasize that "the growth in the number of migrants who can afford to pay high prices for their travels is a decisive factor boosting the smuggling networks". Through the interviews of migrants newly arrived in Europe, Frontex documents that the migrants who reached Italy from Turkey spent on average EUR 5000 per person for smuggling services (Frontex, 2019: 28).

Auriol and Mesnard (2016) introduce the first industrial organization model of the market for smuggling services. The number of smuggler criminal organizations is given; they engage in monopolistic competition à la Cournot, choosing smuggling fees to maximize the profit (rent). The optimal smuggling fee depends on the elasticity of demand and the number of smuggling organizations. Migrants with heterogenous productivity choose between buying a visa and migrate legally, or paying the smuggling fee and migrate illegally.

The majority of existing studies on smuggling focus on the most effective ways to prevent irregular migration (although authorizing for an increasing number of legal migrants might be an interesting mean to increase the welfare of both migrants and host countries as evidenced by Moraga and Rapoport, 2014) and advocate for tighter border control and stricter laborlaw enforcement policies. This orientation reflects the "general understanding that illegal migration only exists because of the smuggling industry, leading to widespread agreement that the industry should be tackled both for humanitarian and strategic reasons" (Friebel et $a l ., 2018)$.

Friebel and Guriev (2006) show that an increase in the strictness of border controls decreases migration of both skilled and unskilled migrants. Tamura (2010) suggests that migratory flows should be restricted by tighter border controls rather than inland controls. In some cases, increasing the probability and sanction for inland migrant exploitation may increase the total number of smugglers, who would shift to providing non-exploitative ser- 
vices. Djajic and Vinogradova (2014) argue that, when migrants can choose how to finance their migration (in a long-run perspective), increasing border-control measures does not have an impact on the total number of smuggled migrants because migrants would switch from debt-bonded migration to self-financed migration. Djajic and Michael (2014) investigate how tougher transit cost over a neighboring country can reduce migration. Auriol and Mesnard (2016) show that a combination of tight border controls with the sale of a large number of visas would be an optimal policy, as it would at the same time limit the number of irregular migrants and prevent excessive concentration of the smuggling market (at the cost of increasing drastically the number of legal migrants). Borjas and Cassidy (2019) show that the legal restrictions on the employment of undocumented workers in the United States of America entail a penalty on the wage of the irregular migrants in the hidden segment of the labor market; similarly, Guriev et al. (2019) show that, in Italy, the effectiveness of immigration policies is linked to labor market regulation (see also Orrenius and Zavodny, 2015).

Previous studies deliver many useful insights on the market for migrant smuggling services, but suffer from some drawbacks. First, most of these analyses do not account for the important trade frictions specific to criminal markets, cannot explain migratory flows including the "push-back" phenomenon (the fact that migrants that are caught during the journey are sent back and may try to cross the border over and over again), ${ }^{4}$ and cannot provide an intertemporal evaluation of the gains and benefits for both smugglers and candidates to migration. The purpose of our study is to address these issues, by developing a dynamic flow model of the market for smuggling services, inspired by the matching labor market model by Pissarides (2000)..$^{5}$ This approach acknowledges the fact that trade frictions are a built-in

\footnotetext{
4 Some witnesses state that some migrants tried to cross border fifteen times or more. See The Economist, August 8, 2019, "Migrant arrivals in Italy have tumbled", online at: www.economist.com/europe/2019/08/08/migrant-arrivals-in-italy-have-tumbled

${ }^{5}$ See also Cahuc et al. (2014) for a clear exposition of this model and its extensions.
} 
characteristic of these illegal and opaque markets. Candidates to migration cannot shop for smugglers in the same way as consumers shop for services. They can wait a long period before they get in touch with a smuggler. The Frontex report (2019) reveals that smugglers make use of social media (pre-dominantly Facebook) to advertise their business. World-ofmouth communications are also an important recruiting channel. Lack of mutual trust might lead to unsuccessful matches even when a first contact is established. This mutual search process has been acknowledged long ago by Salt and Stein (1997). A matching function $\grave{a}$ la Pissarides can therefore be a useful device to model these trade frictions. The original contribution of our paper is to model in an explicit way the trade frictions specific to this opaque market, and to use a flow analysis instead of a traditional stock analysis.

Second, the industrial organization of the market for migrant smuggling services may range from a cartel with large criminal organizations to a competitive market between small (family) firms. A few years ago, Gathman (2008) noticed that since little is known about the supply of smuggler services, both perfect competition and collusive monopoly are interesting modeling strategies. In their industrial organization analysis of the smuggling market, Auriol and Mesnard (2016) consider that the smuggling services are provided by a closed oligopoly of criminal organizations, similar to the drug cartels. Some recent field reports suggest that the alternative assumption of a more competitive organization of the market where independent small businesses can enter freely can be relevant with respect to the new migration routes from the Middle East and the Horn of Africa toward Europe. In a recent report on smuggling in the Mediterranean area, Abdel Aziz et al. (2015: 24) claim that "small and ephemeral groups participate in the business as well as large and highly professionalized networks. The players in the smuggling market can be organized in a large variety of ways, from structured criminal groups to individual occasional smugglers" and also that 
"in general, however, the backbone of the smuggling industry does not seem to be based on highly structured and hierarchical organizations". The UNODC (2018) indicates that these smuggling small businesses are important players in this market, next to the criminal cartels with a strong hierarchical organization. Campana (2018) performed an in-depth empirical analysis of the structure and activities of a smuggling ring operating between the Horn of Africa and Northern Europe via Libya, and revealed that activities are segmented and carried out by localized and rudimentary hierarchies with largely independent and autonomous higher-level smugglers. There are also indications of competition among them. ${ }^{6}$ Therefore, to account for this documented decentralization of the market, in this paper we use a version of the "small firm" matching model. ${ }^{7}$

Third, most of the literature analyzes a relationship between smugglers and migrants, where smugglers take advantage of the migrants. However, Achilli and Sanchez (2017) emphasize the complex nature of the migrants/smugglers relationship. They argue that smugglers, if they care about their profits, are not necessarily the selfish reckless persons that most economic papers tend to suggest. They reveal some form of cooperation between smugglers and migrants, as a "rudimentary form of human security from below". Besides, they show that the financial relationship between the two groups is not necessarily characterized by a debt contract, and that many migrants finance their journey by selling assets (houses) or though loans from relatives. In our model, we introduce some form of negotiation between the smugglers and the migrants (on the level of the smuggling fee), in order to allow for a reasonable mix of self-interest and cooperation, in line with the observations from the field (Achilli and Sanchez, 2017; Frontex, 2019). We also assume that migrants self-finance their

\footnotetext{
${ }^{6}$ See also Sanchez (2017) who presents the social and demographic characteristics of the smugglers acting in the illegal migration business to the US.

${ }^{7}$ Our dynamic model could be extended to the case of a closed cartel of smugglers able to extract positive rents, similar to the "large firm" matching model in labor economics.
} 
migration.

In our model, every day, new locals become candidates to migration; some of them find a smuggler, pay the fee up-front and undertake the risky migration journey. Some will succeed in crossing the borders of the destination countries, while others are caught (with their smugglers) by the authorities and sent back to the country of origin (while the smugglers are convicted). To keep the model as simple as possible, we assume that the number of new candidates to migration at each period is constant, and focus on the steady state equilibrium. The model allows to analyze how the numbers of smugglers and irregular migrants as well as the smuggling fee vary with key policy variables related to the smuggling costs and to the chances of successfully crossing the borders (without being caught by the authorities). As an original development, this paper studies the consequences of various policies not only on the number of irregular migrants reaching the destination countries, but also on the intertemporal utility of the candidates to migration. We mainly analyze the consequences of higher smuggling costs (fixed and variable), and of a higher probability for the migrant and the smuggler to be caught during their journey. The model applies essentially to refugees, who are less sensitive to policies implemented by destinations countries to deter irregular migration, but could be extended to economic irregular migrants.

The remainder of the paper is organized as follows. Section 2 presents the structure of the model and the main assumptions, while the results of the model are provided in Section 3. Section 4 presents the insights from the comparative statics analysis and Section 5 concludes.

\section{The matching function and the intertemporal values}

\subsection{The matching function}

In a two-country world where one country (the destination country) attracts migrants from the other one (the origin country), let $M$ be the number of candidates to irregular migration 
(or potential migrants) at each time period and let $S$ denote the number of smugglers (an endogenous variable in the model). In this paper, we analyze only the most plausible situation in which the number of potential migrants exceeds the number of smugglers, $S<M$. A smuggler can meet more than one migrant, and provide support to the group of migrants he got in touch with. ${ }^{8}$ We denote by $H$ the number of migrants who manage to get in touch with smugglers, with $H \leq M$. We therefore make a distinction between $M$, which includes all candidates to migration and $H$, which counts only the candidates to migration who found a smuggler and can engage in the high-risk migration journey.

In a frictionless market, all migrants would meet a smuggler, $H=M$. In a market with trade frictions, at any time period some migrants do not find a smuggler, thus $H<M$. We assume that these informational frictions can be captured by a matching function inspired by the labor market model (Pissarides, 2000; Petrongolo and Pissarides, 2001), in which the number of successful matches is positively related to the numbers of smugglers and candidates to migration: $H=H(M, S)$, with $\partial H / \partial M>0$ and $\partial H / \partial S>0$. Following the same literature, we assume that the matching function presents constant returns to scale. A Cobb-Douglas function has these desirable properties, and will allow us to obtain analytical expressions for the equilibrium solution. More precisely, we assume that the number of successful matches is given by:

$$
H(M, S)=M^{\alpha} S^{1-\alpha}, \text { with } \alpha \in(0,1),
$$

where $\alpha$ (respectively $1-\alpha$ ) is the elasticity of the number of successful matches with respect to $M$ (respectively $S) .^{9} \quad$ The elasticity $\alpha$ is indicative of the efficiency of the matching process; since $S<M, \partial H / \partial \alpha>0$. For $\alpha=1$, we obtain the special case of the frictionless

\footnotetext{
8 This assumption contrasts with the standard labor market model where if more than one unemployed person apply for a vacant job, only one of them will be accepted.

${ }^{9}$ We can easily check that this function has the correct properties: $\forall \alpha \in(0,1)$ and $S<M, H(M, S) \in$ $(S, M)$.
} 
market; for $\alpha=0, H=S$ : every smuggler meets on average one migrant only. ${ }^{10}$

We define $\theta$ as the smuggler per potential migrant ratio:

$$
\theta=\frac{S}{M} \leq 1
$$

The mean number of smuggled migrants per smuggler is:

$$
h(\theta)=\frac{H(M, S)}{S}=\theta^{-\alpha} \geq 1
$$

with $h^{\prime}(\theta)=-\alpha h(\theta) / \theta \leq 0$.

Given the matching process, the ex-ante probability for a candidate to migration to find a smuggler is:

$$
g(\theta)=\frac{H(M, S)}{M}=\theta^{1-\alpha} \leq 1,
$$

with $g^{\prime}(\theta)=(1-\alpha) h(\theta) \geq 0$.

Obviously, $\theta, h(\theta)$ and $g(\theta)$ are related, the number of candidates to migration who meet a smuggler being equal to the number of smugglers times the mean number of migrants per smuggler:

$$
M g(\theta)=S h(\theta) \Leftrightarrow g(\theta)=\theta h(\theta)
$$

\subsection{The two stages}

The time structure of the model includes two distinct stages. During the first stage, candidates to migration and smugglers strive to meet each other. Migrants search for a smuggler and either find one (with probability $g(\theta)$ ), or don't. At the end of this stage, each smuggler has found on average $h(\theta)$ candidates to migration to be smuggled to the destination country.

During the second stage, those who did not find a smuggler continue searching, and those who found one undertake their dangerous journey from the origin country to the destination

\footnotetext{
10 The Cobb-Douglas specification does not allow us to study a situation where the number of matches is lower than the number of smugglers $(H<S)$. This is not a major restriction as far as the number of smugglers is small relatively to the number of migrants.
} 
country. Smugglers and smuggled migrants have a probability $\pi$ to successfully reach the destination country: at the end of the second stage, they have either reached the destination country, or were stopped by the border police. ${ }^{11}$ In the latter case, candidates to migration are sent back to their origin country, and smugglers are convicted.

Figure 1 presents the flow diagram of the model (from the perspective of the migrants).

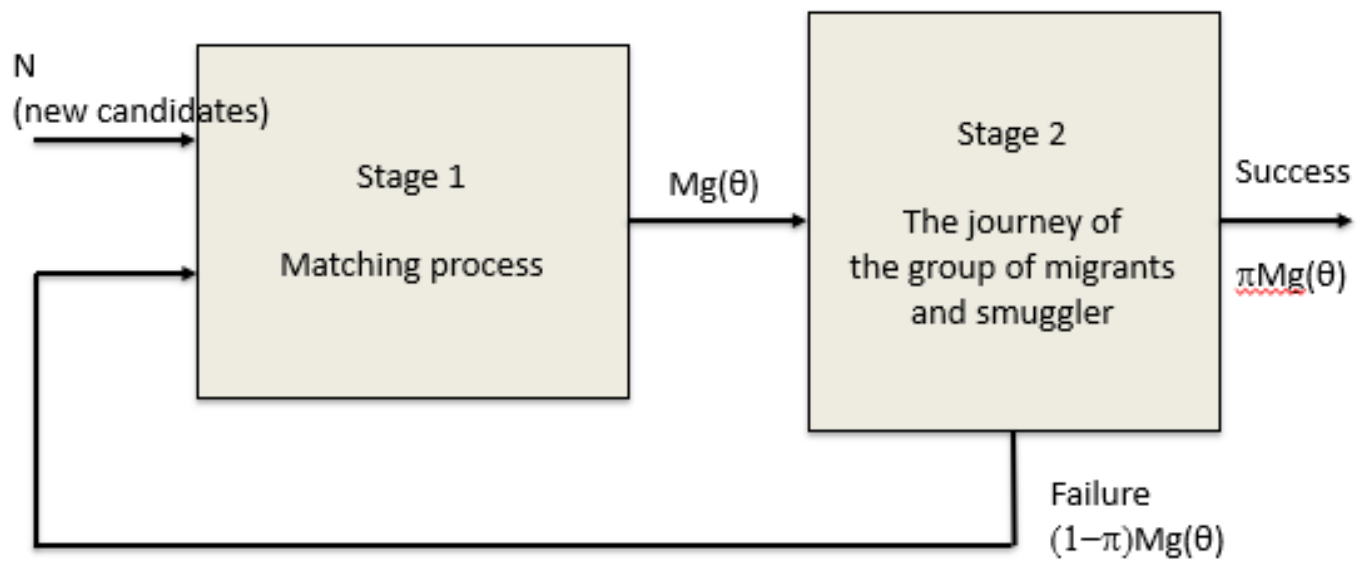

The Flow Diagram

We assume that the number of new candidates to migration is constant and equal to $N$ (it structurally depends on the conditions in the countries of origin of candidates to migration). In this respect, the model fits best the situation of refugees, whose decision to leave the country of origin is not affected by economic variables in the destination countries. An analysis of economic migration could build on this simplified version, by relating $N$ to key economic variables.

At any time $t$, the relationship between the number of candidates to migration $\left(M_{t}\right)$ and the (constant) number of new candidates $(N)$ is:

$$
M_{t}=N+[1-\pi g(\theta)] M_{t-1}
$$

\footnotetext{
11 Smugglers and migrants may also be stopped by other external shocks (natural events, conflicts, etc.), leading them not to reach their destination. It can also be argued that migrants may be caught without their smuggler. This would imply to add another probability for the migrants to be stopped alone. Including this additional parameter would not change the main results of the model.
} 
since the number of candidates to migration at time $t\left(M_{t}\right)$ is the sum of the new candidates $(N)$ and the previous candidates who did not succeed in migrating. The latter group includes those who did not meet a smuggler $\left([1-g(\theta)] M_{t-1}\right)$ and those who met one but did not succeed in crossing the border $\left((1-\pi) g(\theta) M_{t-1}\right)$. Because $[1-\pi g(\theta)]<1$, equation $(6)$ is dynamically stable.

Our analysis focuses on the steady-state (or long-run) equilibrium. The long-run equilibrium number of candidates to migration per period, $M$, is the solution to the recursive equation (6) for $M_{t}=M_{t-1}=M$ :

$$
M=\frac{N}{\pi g(\theta)},
$$

where the ratio $\theta$ is an endogenous variable. After any shock to this dynamic system (due to policy changes for instance), the long run number of candidates to migration will gradually adjust to the new long run value, after a more or less lengthy process.

\subsection{Intertemporal values}

\subsubsection{The intertemporal value of the smuggler}

Let $V^{S}$ be the intertemporal utility of a smuggler who searches for a candidate to migration. At every search period, the smuggler incurs a fixed cost $c$ (advertising his business, planning the best route to migrate and maintaining contacts along the route, corruption...), which might include a stigma of a person involved in illegal activities. On average, in stage 1, he finds $h(\theta)$ candidates to migration, with whom he engages in a risky journey. The journey involves a cost $l$ per migrant (transportation, guiding and escorting during irregular border crossing, shelter along the route, food, bribes, counterfeit documents...).

Abdel Aziz et al. (2015) who studied the migration route in the Mediterranean area, report that for long journeys, the smuggling fee is paid in advance, step by step, through the Hawala or Western Union methods of payment. For other routes, especially for migrants 
coming from West Africa, one-shot and one-border smuggling services are usually purchased at the border with Libya. We thus assume that the smuggler charges (in advance) to the migrant a "smuggling fee" $w$, whether or not the ride is successful. ${ }^{12}$ The cash-in-advance assumption implicitly requires that the migrant can afford to pay this fee; so doing, he has sold assets, used his savings or borrowed from family. However, it must be acknowledged that this negotiated smuggling fee might exceed the immediate cash resources of the migrant. In this case, the migrant will commit to pay the difference later, which is tantamount for him to enter in a debt contract with the smuggler. This additional complexity would not change in a substantial way our conclusions. It would require to add a debt term to be paid to the smuggler only if the migrant successfully crossed the border of the destination country.

During the journey (stage 2), the authorities may catch the smuggler and the migrants with a probability $\eta=(1-\pi), \pi$ being the probability of success. If they are caught, the candidate to migration is sent back to his home country, where he engages again in the search for a smuggler ${ }^{13}$, and the smuggler is sent to jail and pushed out of the smuggling business; this is tantamount to a cost $K>0$ incurred by the smuggler. If they are not caught, the migrant stays in the destination country, and the smuggler comes back to his origin country at the end of the journey and continues his smuggling activities.

Denoting by $r$ the interest rate, we can write the expected intertemporal utility of a smuggler in a brief period of time $d t>0$ as:

$$
V^{S}=[-c+h(\theta)(w-l)] d t+\exp (-r d t)\left[\eta d t(-K)+(1-\eta d t) V^{S}\right]
$$

${ }^{12}$ Tamura (2010), on the opposite, assumes that the fee is paid only if the migrant has been smuggled as agreed. Here, we implicitely assume that there is no commitment issue for the smuggler (he will strive to smuggle the candidate to migration once he is paid).

13 Different reports point out to the outrageous situation where thousands of people die every year on the migration roads (Achily ans Sanchez 2017, EUFRA, 2019). The structure of the problem would not change much if we include in the model a second probability that the migrant dies on the road, to which we associate a highly negative payoff. 
For $d t$ decreasing towards 0 , the former expression simplifies to (see Appendix A1):

$$
V^{S}=\frac{h(\theta)(w-l)-[c+(1-\pi) K]}{r+(1-\pi)} .
$$

$V^{S}$ is a decreasing function of $\theta$ : for a given smuggling fee (higher than the marginal cost of the smuggling activities), if more smugglers enter the market, competition among them becomes more intense, the average number of candidates to migration per smuggler decreases, and the intertemporal utility of the smuggler declines.

\subsubsection{The intertemporal value of the candidate to migration}

Let $V^{M}$ denote the intertemporal utility of a candidate to migration who searches for a smuggler. The candidate to migration has a (small) benefit $z \geq 0$ of living in his country of origin. $z$ may be an official aid for subsistence or the love of the candidate to migration for his country of origin (it could also be negative if the candidate to migration is subject to permanent threats).

In stage 1 , with the probability $g(\theta)$ the candidate to migration finds a smuggler, pays him the smuggling fee $w$ and starts the migration journey. Then, in stage 2 , there is a probability $\pi$ that his/her group of migrants guided by the smuggler successfully crosses the border. In that case, the migrant enjoys the intertemporal value of the successful migration (the discounted flow of his future income in the destination country) denoted by $Y$, which depends on the economic conditions in the destination country, but also on policies implemented in this country to fight against undocumented workers and migrants (Orrenius and Zavodny, 2015; Borjas and Cassidy, 2019; Guriev et al., 2019). However, with probability $(1-\pi)$ the group of migrants is caught and sent back to their country of origin. In that case, they start again to search for a smuggler, along with the candidates to migration who did not find a smuggler in stage 1.

In a brief period of time $d t>0$, the expected intertemporal utility of the migrant (before 
he/she has found a smuggler) is therefore:

$$
V^{M}=[z-g(\theta) w] d t+\exp (-r d t)\left\{\pi g(\theta) d t Y+(1-\pi g(\theta) d t) V^{M}\right\}
$$

For $d t$ decreasing towards 0 , the former expression simplifies to (see Appendix A1):

$$
V^{M}=\frac{z+g(\theta)(\pi Y-w)}{r+\pi g(\theta)} .
$$

$V^{M}$ is an increasing function of $\theta$ :

$$
\begin{aligned}
\frac{d V^{M}}{d \theta} & =\frac{g^{\prime}(\theta)(\pi Y-w)(r+\pi g(\theta))-\pi g^{\prime}(\theta)[z+g(\theta)(\pi Y-w)]}{(r+\pi g(\theta))^{2}} \\
\frac{d V^{M}}{d \theta} & =\frac{r(1-\alpha) h(\theta)}{(r+\pi g(\theta))^{2}}\left[\pi\left(Y-\frac{z}{r}\right)-w\right] \geq 0 .
\end{aligned}
$$

The expression $[\pi(Y-z / r)-w]$ is positive: there would be no candidate to migration if the net expected benefit of a successful migrant were below the smuggling fee. For a given smuggling fee, if the number of smugglers $S$ (and thus $\theta$ ) increases, this is tantamount to a higher probability to find a smuggler for each candidate, and higher competition for migrants between smugglers, which should be beneficial to the former.

\section{Solving the model}

\subsection{The free-entry condition (SS)}

As revealed by the reports surveyed in the introduction, the organization of the smuggling market can be very complex with large cartels and small-business smugglers complementing each other and sometimes fighting to provide similar services (UNODC, 2018). There is recent evidence that, at least in the smuggling market carrying migrants from the Horn of Africa to Europe via Libya, most of the smuggling activity is carried out by small businesses, run by largely independent and autonomous higher-level smugglers that compete between them to provide services to a limited number of candidates to migration (Campana, 2018; Abdel Aziz et al., 2015). The same studies suggest that barriers to entry into this business 
are small; as documented by Sanchez (2017), many smugglers are unsuccessful candidates to migration, who use their experience to settle as mugglers. Field evidence also reveals that smugglers seize very quickly new opportunities to extend their criminal activities, as the opening of the Libyan route to the EU has shown (Friebel et al., 2018).

In line with this empirical evidence, we consider smugglers as entrepreneurs, owners of "small firms" made up of a small number of relatives and close friends. These entrepreneurs in criminal activities can freely and rapidly enter the smuggling market; thus profit from smuggling is quickly driven down to the profit from their best alternative activity, denoted by $v$. When a smuggler is convicted and pushed out of the smuggling business, another smuggler will enter the market, in keeping to the profit indifference condition. This modeling framework is consistent with facts reported by Campana (2018), who notices that "the presence of multiple independent smugglers in competition among themselves makes it likely that, following the removal of an individual smuggler, the remaining smugglers will try to seize this opportunity to acquire his 'market' share".

The free entry condition $V^{S}=v$ determines $\theta$, and thus the number of smugglers $S$, as a function of $w$; this relationship can be seen as a "smuggler supply" (SS) function, $\theta=\theta(w) .{ }^{14}$ For analytical convenience, we prefer to express it as the reciprocal function $w=w(\theta)$.

Using eq. (9), we get:

$$
w=l+\frac{c+v r+(1-\pi)(v+K)}{h(\theta)} .
$$

Because $h$ is decreasing in $\theta$, the relationship between $\theta$ and $w$ is positive. All else equal, a higher fee $w$ would attract more smugglers, thereby increasing $\theta$. A new equilibrium is obtained as the entry of new smugglers decreases $h$, and brings $V^{S}$ down to $v$.

\footnotetext{
14 The free-entry condition is somehow similar to the job-creation condition in the Pissarides (2000) framework; here, smuggler "jobs" are created in the black market.
} 


\subsection{The smuggling fee equation (WN)}

The successful match between the smuggler and the candidate to migration creates value for both of them. How this total surplus is divided between the smuggler and the migrant depends on the fee $w$, as negotiated between them. Rational agents would agree on a Nash Bargaining Solution (Nash, 1950) to determine the outcome of an efficient negotiation, that would not waste any of the surplus. Thus, we implement this solution to determine the negotiated wage.

The Nash maximand is written as:

$$
\Phi=\left\{V^{M}\right\}^{1-\beta}\left\{V^{S}\right\}^{\beta}
$$

where we assume that the statu quo utilities are null, and $\beta$ captures the relative bargaining powers. It seems reasonable to consider that the negotiating power mostly sits with the smugglers, i.e. that $\beta$ is relatively large (although we do not need this assumption to solve the model).

Denoting by $\varphi$ the $\log$ of $\Phi$ and using equations (9) and (11) for $V^{S}$ and $V^{M}$, the Nash maximand becomes:

$$
\begin{aligned}
\varphi= & (1-\beta) \ln \left(\frac{z+g(\theta)(\pi Y-w)}{r+\pi g(\theta)}\right)+\beta \ln \left(\frac{h(\theta)(w-l)-c-(1-\pi) K}{r+(1-\pi)}\right) \\
= & (1-\beta)\{\ln [z+g(\theta)(\pi Y-w)]-\ln [r+\pi g(\theta)]\} \\
& +\beta\{\ln [h(\theta)(w-l)-c-(1-\pi) K]-\ln [r+(1-\pi)]\} .
\end{aligned}
$$

The First Order Condition $\frac{d \varphi}{d w}=0$ yields the negotiated wage $w$ as a function of $\theta$, which we define as the WN relationship:

$$
\begin{aligned}
w & =\beta \pi Y+(1-\beta) l+\frac{\beta z}{g(\theta)}+\frac{(1-\beta)[c+(1-\pi) K]}{h(\theta)} \\
& =\beta\left[\pi Y+\frac{z}{g(\theta)}\right]+\frac{(1-\beta)[c+(1-\pi) K+l h(\theta)]}{h(\theta)} \\
& =\frac{c+h(\theta) l+(1-\pi) K}{h(\theta)}+\beta\left[\pi Y+\frac{z}{g(\theta)}-\frac{c+h(\theta) l+(1-\pi) K}{h(\theta)}\right] .
\end{aligned}
$$


The negotiated fee per migrant $(w)$ covers the expected cost per migrant, plus a profit margin increasing in the smuggler's bargaining power, and in the migrant's expected benefit from migration. It is positive (under the sufficient but not necessary condition $z>0$ ).

The negotiated fee does not vary monotonously with $\theta$ :

$$
\frac{d w}{d \theta}=-\beta z \frac{g^{\prime}(\theta)}{[g(\theta)]^{2}}-(1-\beta)[c+(1-\pi) K] \frac{h^{\prime}(\theta)}{[h(\theta)]^{2}} .
$$

Since $g(\theta)=\theta h(\theta), h^{\prime}(\theta)=-\alpha h(\theta) / \theta$, and $g^{\prime}(\theta)=(1-\alpha) h(\theta)$, we get:

$$
\frac{d w}{d \theta}=-\frac{1}{\theta^{2} h(\theta)}\{(1-\alpha) \beta z-\alpha(1-\beta)[c+(1-\pi) K] \theta\} .
$$

The smuggling fee is an increasing function of $\theta$ when:

$$
\frac{d w}{d \theta} \geq 0 \Leftrightarrow \theta \geq \tilde{\theta} \equiv \frac{1-\alpha}{\alpha} \frac{\beta}{1-\beta} \frac{z}{c+(1-\pi) K} .
$$

So $w$ is decreasing with $\theta$ for $\theta<\tilde{\theta}$ and increasing with $\theta$ for $\theta \geq \tilde{\theta}$. In the special case where smugglers have all the bargaining power $(\beta \rightarrow 1)$, the negotiated fee $w$ is always decreasing with $\theta$.

We can analyze variations in $w$ for a constant $\theta$, or how the curve WN shifts when parameters change. $w$ increases with the marginal and fixed costs $(l$ and $c)$ of the journey, and with the cost $K$ incurred by the smuggler when arrested. It also increases with the intertemporal value $Y$ of successful migration, and the benefit $z$ of the potential migrant in his country of origin. Depending on the parameters, the negotiated fee $w$ may increase or decrease with the probability of success $\pi$ :

$$
\frac{d w}{d \pi}=\beta Y-(1-\beta) \frac{K}{h(\theta)}
$$

If the weighted gain of a successful migration is higher than the cost per migrant incurred by smugglers when arrested $\left(\frac{\beta}{1-\beta} Y \geq \frac{K}{h(\theta)}\right)$, then the smuggling fee increases with the probability of success, and conversely. When smugglers have all the bargaining power $(\beta \rightarrow 1)$, the negotiated fee $w$ unambiguously increases with the probability of success $\pi$. 


\subsection{The equilibrium}

The equilibrium of this flow market is defined as the couple $\left(w^{*}, \theta^{*}\right)$ which simultaneously verifies equations (14) and (18).

Figure 2 represents the two equations and the equilibrium values. Curves were numerically simulated for the following parameter values: $Y=7.5 ; v=5 ; K=2 ; z=0.05$; $r=0.10 ; l=0.50 ; c=0.50 ; \alpha=0.75 ; \pi=0.50$ and $\beta=0.75$. We recall that $\beta>0.5$ suggests that the bargaining power sits with the smugglers. The probability of success of 0.5 used in the simulation acknowledges that many migrants are caught during the journey, and compelled to start their journey several times, a phenomenon referred to as "push back".

With these parameter values, the equilibrium smuggling fee is $w^{*}=3.20$ and the smuggler per potential migrant ratio is $\theta^{*}=0.50$.

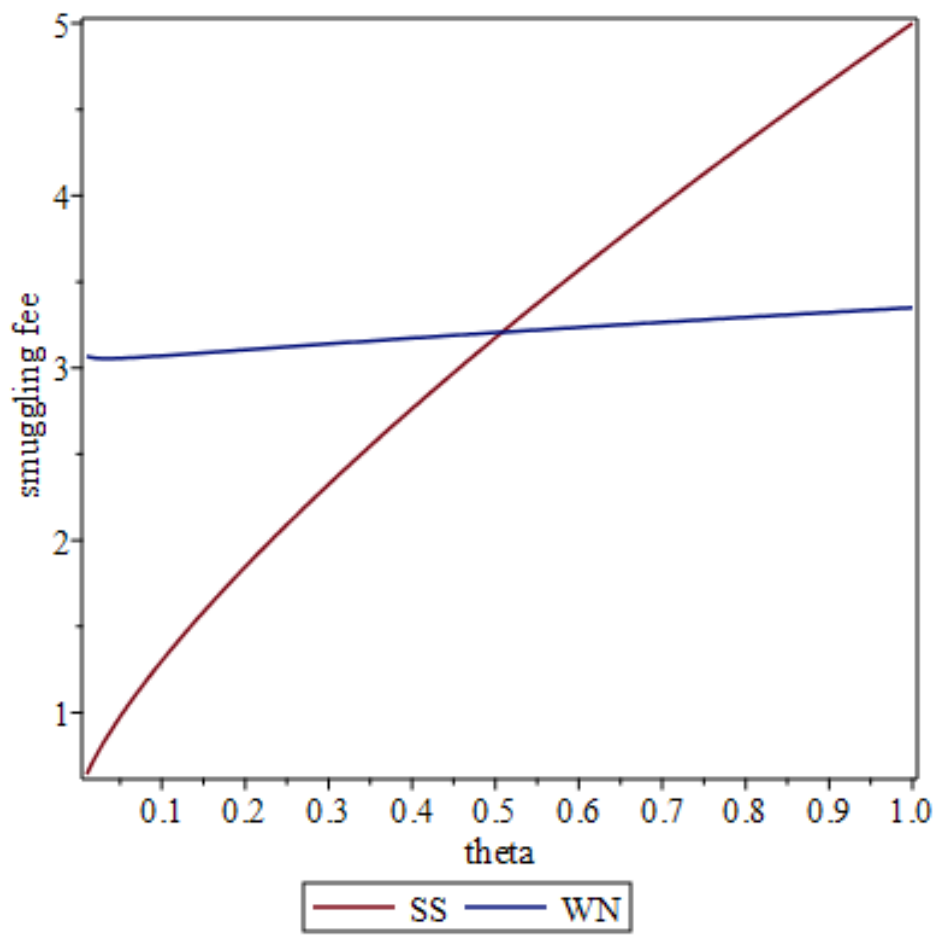

Equilibrium in the smuggling market

The definitions of $V^{S}$ and $V^{M}$ used to build the model require that there are more can- 
didates to migration than smugglers on the market, i.e. $\theta<1$. As the numerical simulation in Figure 2 shows, such an equilibrium can exist for meaningful parameter values. In the Proof of Proposition 1, we present the formal restriction on parameters that guarantees the existence of the solution.

Proposition 1 If a solution $\theta^{*} \in(0,1)$ exists, it is unique (under the sufficient condition $z \geq 0$ ).

Proof. The implicit definition of $\theta^{*}$ is given by equalizing wages in equations (14) and (18):

$$
\begin{aligned}
l+\frac{c+(r+1-\pi) v+(1-\pi) K}{h(\theta)} & =\beta \pi Y+(1-\beta) l+\frac{\beta z}{g(\theta)}+\frac{(1-\beta)[c+(1-\pi) K]_{5}}{h(\theta)} \\
\underbrace{(r+1-\pi) v+\beta[c+(1-\pi) K]}_{L H S} & =\underbrace{\beta\left[(\pi Y-l) h(\theta)+\frac{z}{\theta}\right]}_{\text {RHS }(\theta)} .
\end{aligned}
$$

The LHS term is independent of $\theta$ and positive. For $z \geq 0$, since $h(\theta)=\theta^{-\alpha}$ is decreasing in $\theta, R H S$ is decreasing in $\theta$, with $\lim _{\theta \rightarrow 0^{+}} R H S(\theta)=+\infty$ and $\lim _{\theta \rightarrow+\infty} R H S(\theta)=0$. Then equation (26) has a unique solution $\theta^{*}$ in $[0 ;+\infty[$.

The solution $\theta^{*}$ is lower than 1 if and only if $L H S \geq R H S(1)$. This can be expressed as a condition over the probability of success $\pi$ :

$$
(r+1-\pi) v+\beta[c+(1-\pi) K] \geq \beta(\pi Y-l+z) \Leftrightarrow \pi \leq \hat{\pi} \equiv \frac{(1+r) v+\beta(c+l+K-z)}{v+\beta(Y+K)}
$$

For $z \geq 0$, if $\pi \leq \hat{\pi}$, then there exists a unique solution $\theta^{*} \in(0,1)$.

\section{Comparative statics}

Policies implemented by the destination country to fight against illegal border crossing may impact the cost of smuggling activities ( $c$ and $l$ ) as well as the probability of success $(\pi)$. Policies aiming at containing irregular employment have an impact on the economic gains associated with irregular migration $(Y)$. These two kinds of policies in turn impact the equilibrium number of smugglers, given by the equilibrium ratio $\theta^{*}$, as well as the mean 
number of smuggled migrants per smuggler, the final number of smuggled migrants and the smuggling fee. They also have an impact on the welfare of the candidates to migration.

\subsection{The impact of policies on the equilibrium $\theta^{*}, h^{*}$, and $w^{*}$.}

Proposition 2 In the equilibrium, the ratio of smugglers per potential migrant $\theta^{*}$ is increasing in $Y$ and $\pi$, and decreasing in $c, l$ and $K$ (under the sufficient condition $z \geq 0$ ).

Proof. Cf. Appendix A.2.

Corollary 3 The equilibrium number of smuggled migrants per smuggler $h^{*}$ is decreasing in $Y$ and $\pi$, and increasing in $c, l$ and $K$ (under the sufficient condition $z \geq 0$ ).

Proof. It follows from the fact that the equilibrium mean number of smuggled migrants per smuggler $h^{*}=\left(\theta^{*}\right)^{-\alpha}$ is decreasing in $\theta$.

The equilibrium smuggling fee $w^{*}=w\left(\theta^{*}\right)$ can be determined by means of any of the two wage expressions (eq. 14 or 18).

Proposition 4 In the equilibrium, the smuggling fee $w^{*}$ is increasing in $Y, c, l$ and $K$ (under the sufficient condition $z \geq 0$ ). With respect to $\pi$, its variations are ambiguous (depending on the parameters).

Proof. Cf. Appendix A.3.

Increasing the costs of smuggling activities will lead to an increase in the smuggling fee paid by migrants to smugglers. These results are similar to those of Auriol and Mesnard (2016). Besides, decreasing the gains associated with migration leads to a decrease in the smuggling fee.

However, how the equilibrium smuggling fee reacts to a stricter border control that would decrease the probability of successfully crossing borders depends on the parameters of the problem. On the one hand, if the probability of success $(\pi)$ increases, then the expected gains of a successful migration $(\pi Y)$ increase, driving up the smuggling fee. On the other hand, 
this increase in the probability implies a decrease in the expected cost of being convicted for the smuggler $(-\pi K)$, driving down the smuggling fee. Such complex responses of important endogenous variables to changes in key parameters are not uncommon in matching models, and in general are addressed by calibration and numerical simulations.

\subsection{A discussion of the short-run impact of policies}

Most of the migration policies are unfortunately implemented to address short run tensions. In the short run, the number of candidates to migration $M$ can be seen as invariant ("sticky"), as policies will have an immediate effect on $\theta^{*}$ (via the fast adjustment of the number of smugglers) and $w^{*}$. In the long run, after an initial policy shock, $M$ will gradually converge toward its new value as determined by equation (7).

For the equilibrium ratio $\theta^{*}$, we can define the short-run number of smugglers by $s^{*}=$ $M \theta^{*}$ and the short-run number of successful irregular migrants by $m^{*}=\pi M g\left(\theta^{*}\right)$.

Proposition 5 In the short-run, the number of successful irregular migrants $m^{*}$ is increasing in $Y$ and $\pi$, and decreasing in $c, l$ and $K$ (under the sufficient condition $z \geq 0$ ).

Proof. For a given number of candidates to migration, the equilibrium number of successfully smuggled migrants is $m^{*}=\pi M g\left(\theta^{*}\right)$. Since $M$ is constant and $g$ is positive and increasing in $\theta^{*}$, Proposition 2 implies that the final number of smuggled migrants increases with the intertemporal value of successful migration $(Y)$ and the probability of successful migration $(\pi)$ but decreases with the fixed $(c)$ and marginal $(l)$ costs of smuggling activities and the intertemporal cost of being arrested $(K)$.

In the long-run, the number of successful migrants is constant and equal to $N$ : from equation (7), we have $\pi M g\left(\theta^{*}\right)=N$; all the candidates eventually succeed in migrating, because they try over and over again. 


\subsection{The welfare of the candidates to migration}

Finally, we are interested in the effect of parameter changes on the welfare of candidates to migration as resulting from this equilibrium.

The net expected intertemporal utility of a (risk-neutral) candidate to migration will feature three expected states of nature: he/she may either succeed in reaching the destination country (with probability $\pi g\left(\theta^{*}\right)$ ), or fail to reach the destination, either because he/she did not find a smuggler (with probability $\left[1-g\left(\theta^{*}\right)\right]$ ), or because the journey was discontinued (with probability $(1-\pi) g\left(\theta^{*}\right)$ ). Denoting the equilibrium net expected intertemporal utility by $W^{*}$, it can be expressed as:

$$
\begin{aligned}
W^{*} & =\pi g\left(\theta^{*}\right)\left(Y-w^{*}-\frac{z}{r}\right)+\left[1-g\left(\theta^{*}\right)\right] V^{M}\left(\theta^{*}, w^{*}\right)+(1-\pi) g\left(\theta^{*}\right)\left[V^{M}\left(\theta^{*}, w^{*}\right)-(208)\right) \\
& =\pi g\left(\theta^{*}\right)\left(Y-w^{*}-\frac{z}{r}\right)+\left[1-\pi g\left(\theta^{*}\right)\right] V^{M}\left(\theta^{*}, w^{*}\right)-(1-\pi) g\left(\theta^{*}\right) w^{*} \\
& =\pi g\left(\theta^{*}\right)\left[Y-\frac{z}{r}-\frac{w^{*}}{\pi}-V^{M}\left(\theta^{*}, w^{*}\right)\right]+V^{M}\left(\theta^{*}, w^{*}\right)
\end{aligned}
$$

Proposition 6 The expected intertemporal utility of a risk-neutral candidate to migration $W^{*}$ is increasing in $Y$, and decreasing in $c, l$ and $K$ (under the sufficient condition $z \geq 0$ ). With respect to $\pi$, its variations cannot be determined analytically.

Proof. Cf. Appendix A.4.

Any policy increasing the fixed $(c)$ and marginal $(l)$ costs of smuggling activities, as well as the cost of being arrested $(K)$ would result in a decrease in the expected utility of the candidate to migration: on the one hand, with higher costs the number of smugglers entering this market is cut down, which reduces chances of the candidates to migration to reach the destination country; on the other hand, smugglers remaining in the market will transfer part of the higher costs to the migrants, charging a higher smuggling fee. While the first effect could be in line with the usual goals of policymakers of the destination country, the second effect is a pure deterioration of the migrant's welfare, that further draws them into economic 
fragility.

Employment controls and reduced social benefits in the destination country that reduce $Y$ would also deteriorate the net expected utility of the candidate to migration, even if the smuggling fee is decreased by these policies.

However, due to the complexity of the relationships specific to the matching model, the welfare effect of a change in the probability of success $(\pi)$ cannot be determined analytically, in particular because the effect of the change in $\pi$ on the equilibrium smuggling fee is ambiguous (depends on parameters).

In the short run, $M$ is given and changes in the individual expected utility can be interpreted as changes in the overall welfare measured by an utilitarian collective welfare function. The long run consequences of changes in parameters are more difficult to infer, since they impact not only the expected welfare of the candidates to migration, but also $M$, the total number of candidates to migration, according to equation (7).

Table 1 summarizes the main effects of parameter changes on the endogenous variables, as determined analytically.

\begin{tabular}{|l|l|l|l|l|l|}
\hline & $c$ & $l$ & $K$ & $Y$ & $\pi$ \\
\hline$\theta^{*}$ & - & - & - & + & + \\
\hline$h^{*}$ & + & + & + & - & - \\
\hline$g^{*}$ & - & - & - & + & + \\
\hline$m^{*}$ & - & - & - & + & + \\
\hline$w^{*}$ & + & + & + & + & $?$ \\
\hline$W^{*}$ & - & - & - & + & $?$ \\
\hline
\end{tabular}

Table 1: Summary of the main policy effects. Note: short run effect for $\mathrm{W}^{*}$ and $\mathrm{m}^{*}$

\subsection{Numerical simulations}

To remove the ambiguities related to the effect of the probability of success on the smuggling fee and the short-run migrant welfare, we follow a standard approach in matching models by implementing a numerical simulation. It goes beyond the purpose of this paper to provide a 
precise calibration of the parameters. However, we make sure to have plausible parameters, in line with the restrictions imposed by the theory.

Figures 3 and 4 present the evolution of the equilibrium smuggling fee $\left(w^{*}\right)$ and the equilibrium migrant welfare $\left(W^{*}\right)$, varying the probability of success from 0.33 to 0.60 (the upper bound is given by the restriction $\theta<1$; see Proof of Proposition 1). The other parameters are similar to those used to draw Figure 1.

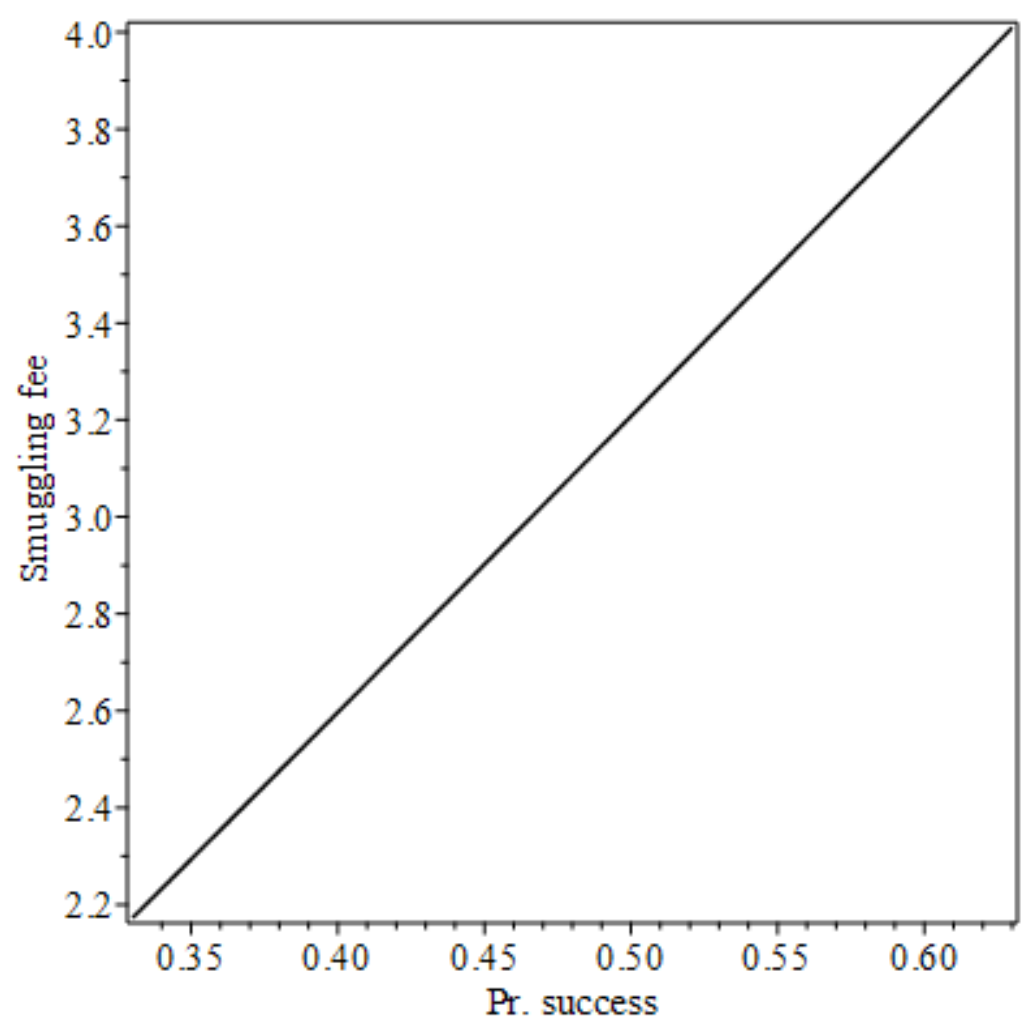

Equilibrium smuggling fee by probability of success 


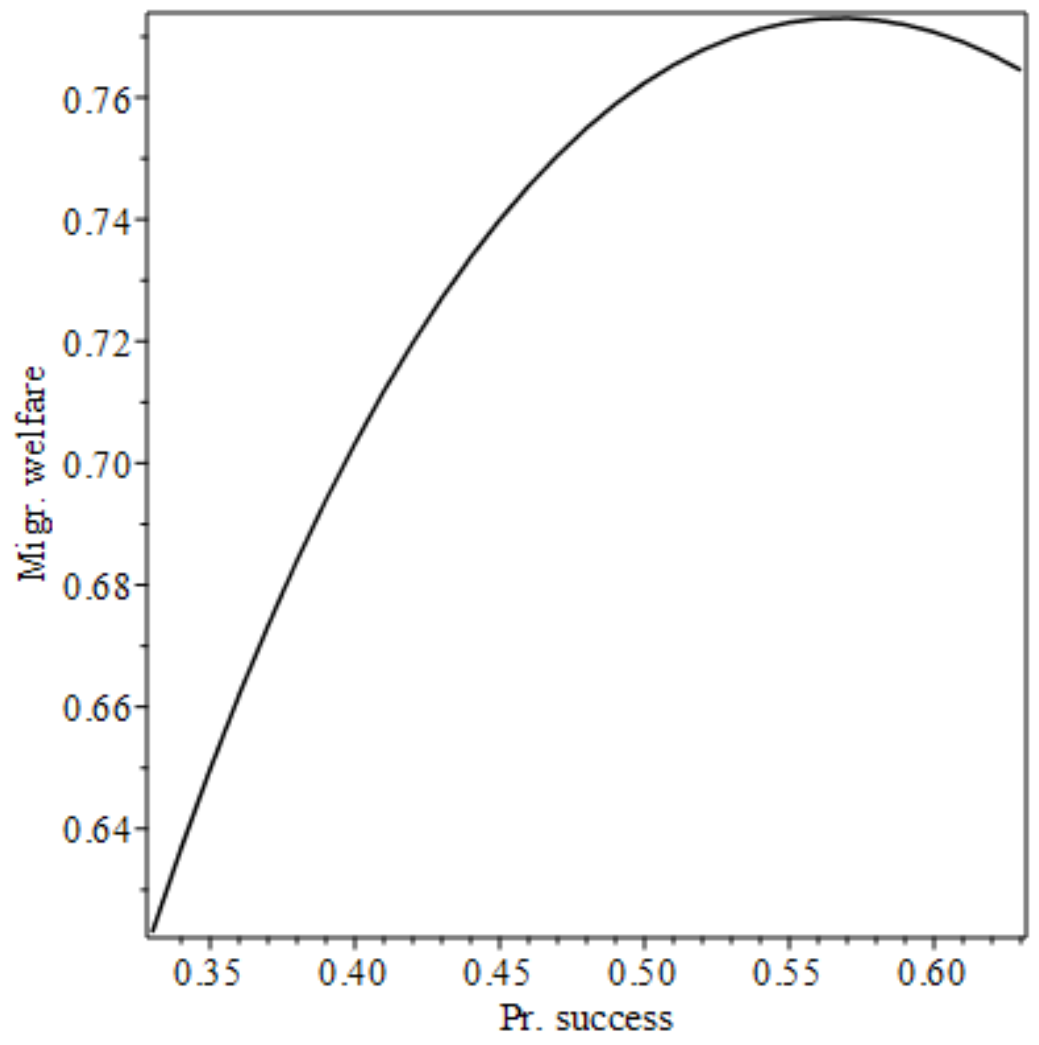

Migrant welfare by probability of success

With these plausible parameter values, the smuggling fee is increasing in the probability of success. This would explain the hump shape of the welfare function: for an extremely high probability of success, the smuggler fee increases so much that the short run welfare of the candidates to migration is actually decreasing (for a given number of candidates to migration). This counterintuitive result is robust to changes in parameters around the values of our simulation. ${ }^{15}$

\section{Conclusion and policy implications}

Irregular migration and migrant smuggling are two facets of the same phenomenon, and control of the former involves an action on the latter. Early studies have analyzed the market for smuggling services as a typical supply and demand problem. While static supply and de-

\footnotetext{
15 The Maple instructions can be provided upon request.
} 
mand models are quite useful in analyzing transparent markets with flexible prices and bring about many useful insights, migrant smuggling, as any illegal activity, is an opaque business, prone to significant trade frictions. Furthermore, it involves massive flows of candidates to migration, trying to meet those smugglers and ready to cross the borders several times until they eventually succeed in reaching the destination country. We argue in this paper that the labor market matching model (Pissarides, 2000) is best suited to analyze such a flow market with trade frictions.

In our model, candidates to migration have no choice but to leave their country, while destination countries do not open their borders. Therefore the only option left to these candidates to migration is to engage in irregular migration, with the support of "professionals" of illegal border crossing, the smugglers. A first industrial organization model of the market for smuggling services was introduced by Auriol and Mesnard (2016), who analyzed the optimal pricing policies of smuggling organizations in an oligopoly market. Recent empirical evidence on irregular migration from Africa to Northern Europe suggests that smugglers often are organized as small businesses with a large degree of autonomy and independence (Abdel Aziz et al., 2015; Sanchez, 2017, Campana, 2018). We therefore build our analysis on the alternative assumption of a competitive segment of the smuggling sector, where criminals organized as small family firms can enter freely the smuggling sector until their profits fall down to the best alternative income. Candidates to migration meet smugglers with a matching probability that depends on the frictions in the market. We model the matching process by means of an original matching function inspired by the literature in labor economics, and solve the model at the steady state equilibrium for the endogenous number of smugglers, the probability of meeting a smuggler and the smuggling fee.

As expected, the numbers of smugglers, successful matches and migrants reaching desti- 
nation decrease with the costs associated to the smuggling activity. In particular, increasing the controls and the cost of being arrested for the smuggler, and the probability to catch the smuggler and the migrants during the journey, should contribute to reducing the number of incoming migrants (in the short run). These findings are in line with the results of existing studies. Our analysis allows to study the effect of these policies on the smuggling fee, and warns policymakers on the dramatic consequences of a raising burden on migrants that are already in an extremely fragile situation.

Most of the previous analyses neglect the perspective of the candidates to migration, who, in many cases, have no option but to leave their country of origin or be exposed to life threats and/or unbearable poverty. Thus, we use the model to provide a migrant welfare analysis. As expected, higher costs of migration are eroding migrant welfare. Numerical simulations show that the probability of succeeding, itself related to the means used by developed countries to catch migrants and push them back, has an ambiguous effect. As expected, low probabilities of success have a negative impact on migrant welfare. However, high probabilities of success might have a detrimental impact on the welfare of the candidates to migration, mainly because it would raise the smuggling fee.

In the last few years, in particular after 2011, the massive migration flows across the Mediterranean sea toward the EU countries, in extremely difficult conditions for the migrants, stuck in rusty boats abandoned by the smugglers at the mercy of the tempests, led to a surge in private humanitarian initiatives. Many NGOs financed search and rescue vessels to patrol next to the Libyan borders, and provide life support to migrants under distress, then ship them to safe harbors, most often in Italy. According to the report of the EU Agency on Fundamental Rights (EUFRA, 2019), while in 2016 there were approximately 22 ships engaged in such activities, because of the legal actions by EU governments against 
these NGOs, in 2019 the number of actually operating ships declined to no more than three. In general, these rescue initiatives solicited significant controversies. Our model may allow to better understand the multiple consequences of the presence of these rescue ships in the Mediterranean. On the one hand, by lowering transportation costs and increasing the probability of success, these initiatives raise the rents of the smugglers (in the first place), and will attract more smugglers in this activity, something that EU governments would like to avoid. On the other hand, more migrants will successfully cross the sea, as chances to meet a smuggler edge up; however, if lower transportation costs drive down the smuggling fee (and thus increase the welfare of the candidates to migration), the effect of a higher probability of success on the smuggling fee is ambiguous, and one cannot rule out that higher smuggling fees can, to some extent, deteriorate migrant welfare.

These conclusions are not independent from our assumptions, and some are more challenging than others. In our model, the probability of catching the migrants at the border is exogenously given, and depends only on the resources allocated to the border and maritime police. A more realistic model would link this probability to the size of the group of migrants that a smuggler will guide. We did not explicitly formalize the possibility that sometimes the journey ends in a dramatic way, with migrants losing their lives, in particular when crossing seas. Also, restrictive policies can have an impact on the number of candidates to migration, in particular when the motive is economic. While in this paper we made the choice of simplicity in order to emphasize the role of trading frictions and the flow dynamics of this market, the simple matching model used here might be modified to take into account these features.

\section{References}

Abdel Aziz Nourhan, Monzini Paola and Pastore Ferruccio, 2015. The Changing Dynamics of Cross-border Human Smuggling and Trafficking in the Mediterranean, Insti- 
tuto Affari Internazionali, Rome, www.iai.it/sites/default/files/newmed_monzini.pdf. Achilli, Luigi and Gabriella Sanchez, 2017. Methodological approaches in human smuggling research: Documenting irregular migration facilitation in the Americas and the Middle East, Migration Policy Practice, 7, 2: 21-25.

Ambrosini, M., 2016. Irregular Migration and Invisible Welfare. Springer.

Auriol, Emmanuelle, and Alice Mesnard, 2016. Sale of visas: A smuggler's final song?, Economica, 83: 646-678.

Borjas, George J., and Hugh Cassidy, 2019. The wage penalty to undocumented immigration. Labour Economics, 61 (forthcoming).

Cahuc, Pierre, Stéphane Carcillo, and André Zylberberg, 2014. Labor Economics. MIT Press.

Campana Paolo, 2018. Out of Africa: The organization of migrant smuggling across the Mediterranean, European Journal of Criminology, 15, 4: 481-502

Djajić, Slobodan, and Alexandra Vinogradova, 2014. Liquidity-constrained migrants, Journal of International Economics, 93, 1: 210-224

Djajić, Slobodan, and Alexandra Vinogradova, 2019. Immigration policies and the choice between documented and undocumented migration, Economica, 86, 341: 201228.

Djajić, Slobodan, and Michael S. Michael, 2014. Controlling illegal immigration: on the scope for cooperation with a transit country, Review of International Economics 22, 4: $808-824$.

Europol, 2016. Migrant Smuggling in the EU, www.europol.europa.eu/ publicationsdocuments/ migrant-smuggling-in-eu.

EUFRA, 2019. 2019 update - NGO ships involved in search and rescue in the Mediterranean and criminal investigations, EU Agency for Fundamental Rights, Viena, Austria. https://fra.europa.eu/en/publication/2019/2019-update-ngos-sar-activities.

Friebel, G, M. Manchin, M. Mendola and G. Prarolo, 2018. International migration intentions and illegal costs: Evidence using Africa-to-Europe smuggling routes, CEPR Discussion Paper 13326.

Friebel, G., S. Guriev, 2006. Smuggling humans: a theory of debt-financed migration, Journal of the European Economics Association, 4: 1085-1111

Frontex, 2019. Risk Analysis for 2019. Risk Analysis Unit, Frontex - European Border and Coast Guard Agency, Warsaw, Poland. https://frontex.europa.eu/assets/Publications/Risk_Analysis/Risk_Analysis/Risk_Analysis_for_20

Gathmann, Christina, 2008. Effects of enforcement on illegal markets: Evidence from migrant smuggling along the southwestern border, Journal of Public Economics, 92: $1926-1941$. 
Guriev, Sergei, Biagio Speciale, and Michele Tuccio, 2019. How do regulated and unregulated labor markets respond to shocks? Evidence from immigrants during the Great Recession, The Journal of Law, Economics, and Organization, 35, 1: 37-76.

IOM, 2019. Glossary on Migration. International Organization for Migration, Geneva, Swtizerland. https://publications.iom.int/system/files/pdf/iml_34_glossary.pdf

McAuliffe M.L. and F. Laczko, 2016. Migrant Smuggling Data and Research: A Global Review of the Emerging Evidence Base, International Office on Migrations, Geneva, Swizerland.

Moraga, Jesús Fernández-Huertas, and Hillel Rapoport, 2014. Tradable immigration quotas, Journal of Public Economics, 115: 94-108.

Naiditch, Claire, and Radu Vranceanu, 2017. The legal grounds of irregular migration: A global game approach. BE Journal of Economic Analysis 8 Policy 17, 2.

Nash John F., 1950. The bargaining problem, Econometrica 18: 155-62.

Orrenius, Pia, and Madeline Zavodny, 2015. Undocumented immigration and human trafficking. In: Handbook of the Economics of International Migration (vol. 1A), Eds. Barry R. Chiswick and Paul W. Miller, Elsevier, Amsterdam: 659-716.

Petrongolo, Barbara and Christopher A. Pissarides, 2001. Looking into the black box: A survey of the matching function, Journal of Economic Literature, 39, 2, 390-431.

Petros, M., 2005. The Cost of Human Smuggling and Trafficking. Global Migration Perspective, Report No. 31, UN Global Commission on International Migration, Geneva.

Pissarides, C. A., 2000. Equilibrium Unemployment Theory, second edition, Cambridge Mass.

Salt, J. and J. Stein, 1997. Migration as a business: The case of trafficking. International Migration, 35, 4: 467-494.

Sanchez, Gabriella, 2017. Critical perspectives on clandestine migration facilitation: An overview of migrant smuggling research, Journal on Migration and Human Security, 5, 1: $9-27$.

Tamura, Yuji, 2010. Migrant smuggling, Journal of Public Economics, 94: 540-548.

Tamura, Yuji, 2013. Migrant smuggling when exploitation is private information. Canadian Journal of Economics / Revue Canadienne d'Economie, 46, 4: 1463-1479.

UNODC, 2018. Global Study on Smuggling of Migrants, United Nations Office on Drugs and Crime, Vienna.

Vespe, Michele, Fabrizio Natale and Luca Pappalardo, 2017. Data sets on irregular migration and irregular migrants in the European Union, Migration Policy Practice, 7 , 2: 26-33. 


\section{A Appendix}

\section{A.1 Intertemporal values, continous time}

\section{The intertemporal value of the smuggler}

In a brief time period $d t>0$, in stage 1 (see Figure 1 ), the representative smuggler incurs the fixed cost $c$, and meets $h(\theta)$ candidates to migration who pays him the smuggling fee $w$; the smuggler also spends the variable cost $l$ per matched migrant. In the second stage, the smuggler may get caught while crossing the border (with probability $\eta d t$ ) and then incurs the intertemporal cost $K$; with the complementary probability $(1-\eta d t)$, he reaches his destination and comes back to his country of origin where he goes on with his smuggling activity. Thus, in a brief time period $d t$, the expected intertemporal utility of the smuggler can be written:

$$
V^{S}=[-c+h(\theta)(w-l)] d t+\exp (-r d t)\left[\eta d t(-K)+(1-\eta d t) V^{S}\right]
$$

For small values of $d t$, we can use the approximation $\exp (-r d t)=\frac{1}{1+r d t}$. Thus, the former expression becomes (replacing $\eta$ with $1-\pi$ when necessary):

$$
\begin{aligned}
V^{S} & =[h(\theta)(w-l)-c] d t+\frac{1}{1+r d t}\left[(1-\eta d t) V^{S}-\eta d t K\right] \\
(1+r d t) V^{S} & =[h(\theta)(w-l)-c](1+r d t) d t+(1-\eta d t) V^{S}-\eta d t K \\
(r+\eta) d t V^{S} & =[h(\theta)(w-l)-c](1+r d t) d t-\eta d t K \\
V^{S} & =\frac{[h(\theta)(w-l)-c](1+r d t)-(1-\pi) K}{r+(1-\pi)} .
\end{aligned}
$$

With $d t$ decreasing towards 0 , the former expression simplifies to:

$$
V^{S}=\frac{h(\theta)(w-l)-[c+(1-\pi) K]}{r+(1-\pi)}
$$

which is equation (9) in the main text.

The intertemporal value of the migrant 
In the brief time period $d t>0$, in stage 1 (see Figure 1), the candidate to migration receives $z$. With probability $(1-g(\theta))$, the candidate to migration does not find a smuggler; with the complementary probability $g(\theta)$, he finds a smuggler and pays him $w$. In the second stage, the candidates to migration who found a smuggler and succeed in reaching the destination country $(\pi g(\theta) d t)$ get $Y$, all the others $(1-\pi g(\theta) d t)$ get $V^{M}$. Thus, in a brief time period $d t$, we have:

$$
\begin{aligned}
V^{M} & =[z-g(\theta) w] d t+\exp (-r d t)\left\{\pi g(\theta) d t Y+(1-\pi g(\theta) d t) V^{M}(\mathrm{~A} .37)\right. \\
V^{M} & =[z-g(\theta) w] d t+\frac{1}{1+r d t}\left\{\pi g(\theta) d t Y+(1-\pi g(\theta) d t) V^{M}\right\} \\
(1+r d t) V^{M} & =[z-g(\theta) w](1+r d t) d t+\pi g(\theta) d t Y+(1-\pi g(\theta) d t) V^{M} \\
(r+\pi g(\theta)) d t V^{M} & =[z-g(\theta) w](1+r d t) d t+\pi g(\theta) d t Y \\
V^{M} & =\frac{[z-g(\theta) w](1+r d t)+\pi g(\theta) Y}{r+\pi g(\theta)} .
\end{aligned}
$$

With $d t$ decreasing towards 0 , the expression simplifies to:

$$
V^{M}=\frac{z+g(\theta)(\pi Y-w)}{r+\pi g(\theta)}
$$

which is equation (11) in the main text.

\section{A.2 Proof of Proposition 2 on $\theta^{*}$}

Proof. The equilibrium smuggler per potential migrant ratio $\theta^{*}$ is implicitely given by eq.

(26). Differentiating this expression with respect to the parameters, we get:

$$
\begin{aligned}
\beta d c+(1-\pi) \beta d K-(v+\beta K) d \pi= & \beta h\left(\theta^{*}\right)(Y d \pi+\pi d Y-d l)-\beta k\left(\theta^{*}\right) d \theta^{*} \\
k\left(\theta^{*}\right) d \theta^{*}= & -d c-(1-\pi) d K+\pi h\left(\theta^{*}\right) d Y-h\left(\theta^{*}\right) d(l) \\
& +\frac{1}{\beta}\left[\beta K+\beta Y h\left(\theta^{*}\right)+v\right] d \pi
\end{aligned}
$$


with $k\left(\theta^{*}\right)=\frac{z}{\left(\theta^{*}\right)^{2}}-(\pi Y-l) h^{\prime}\left(\theta^{*}\right)$. For $z>0$, we know that $k\left(\theta^{*}\right) \geq 0$. Thus, we get:

$$
\begin{aligned}
\frac{d \theta^{*}}{d Y}=\frac{\pi h\left(\theta^{*}\right)}{k\left(\theta^{*}\right)} \geq 0 & \frac{d \theta^{*}}{d c}=-\frac{1}{k\left(\theta^{*}\right)} \leq 0 \\
\frac{d \theta^{*}}{d \pi}=\frac{\beta K+\beta Y h\left(\theta^{*}\right)+v}{\beta k\left(\theta^{*}\right)} \geq 0 & \frac{d \theta^{*}}{d l}=-\frac{h\left(\theta^{*}\right)}{k\left(\theta^{*}\right)} \leq 0 \\
& \frac{d \theta^{*}}{d K}=-\frac{1-\pi}{k\left(\theta^{*}\right)} \leq 0 .
\end{aligned}
$$

\section{A.3 Proof of Proposition 4 on $w^{*}$}

Proof. Equation (14) gives the equilibirum smuggling fee as a function of the equilibrium ratio $\theta^{*}$ :

$$
w^{*}=l+\frac{c+(r+1-\pi) v+(1-\pi) K}{h\left(\theta^{*}\right)} .
$$

Since $h^{\prime}\left(\theta^{*}\right)=-\alpha h\left(\theta^{*}\right) / \theta^{*}$, denoting $A=\alpha[c+(r+1-\pi) v+(1-\pi) K] \geq 0$, the partial derivative of the equilibrium smuggling fee with respect to $Y$ is:

$$
\frac{\partial w^{*}}{\partial Y}=\frac{A}{\theta^{*} h\left(\theta^{*}\right)} \frac{\partial \theta^{*}}{\partial Y} \geq 0
$$

Thus, $w^{*}$ is increasing in $Y$.

Similarly, the partial derivatives of the equilibrium smuggling fee with respect to $c, l$ and $K$ are:

$$
\left\{\begin{aligned}
\frac{\partial w^{*}}{\partial c} & =\frac{1}{h\left(\theta^{*}\right)}\left[1+\frac{A}{\theta^{*}} \frac{\partial \theta^{*}}{\partial c}\right] \\
\frac{\partial w^{*}}{\partial l} & =1+\frac{A}{\theta^{*} h\left(\theta^{*}\right)} \frac{\partial \theta^{*}}{\partial l} \\
\frac{\partial w^{*}}{\partial K} & =\frac{1}{h\left(\theta^{*}\right)}\left[1-\pi+\frac{A}{\theta^{*}} \frac{\partial \theta^{*}}{\partial K}\right] .
\end{aligned}\right.
$$

Replacing the derivatives of $\theta^{*}$ by their expressions given by eq. (46), we get:

$$
\left\{\begin{aligned}
\frac{\partial w^{*}}{\partial c} & =\frac{1}{h\left(\theta^{*}\right)}\left[1-\frac{A}{\theta^{*} k\left(\theta^{*}\right)}\right] \\
\frac{\partial w^{*}}{\partial l} & =1-\frac{A}{\theta^{*} k\left(\theta^{*}\right)} \\
\frac{\partial w^{*}}{\partial K} & =\frac{1-\pi}{h\left(\theta^{*}\right)}\left[1-\frac{A}{\theta^{*} k\left(\theta^{*}\right)}\right] .
\end{aligned}\right.
$$


Yet we know that $\theta^{*} k\left(\theta^{*}\right)=\frac{z}{\theta^{*}}+\alpha(\pi Y-l) h\left(\theta^{*}\right) \geq 0$ and $A=\alpha[c+(r+1-\pi) v+(1-\pi) K] \geq$ 0.

Using eq. (26) defining implicitely $\theta^{*}$, we can rewrite $\theta^{*} k\left(\theta^{*}\right)$ :

$$
\begin{aligned}
(r+1-\pi) v+\beta[c+(1-\pi) K] & =\beta\left[(\pi Y-l) h\left(\theta^{*}\right)+\frac{z}{\theta^{*}}\right] \\
(r+1-\pi) v+\beta[c+(1-\pi) K] & =\frac{\beta}{\alpha}\{\underbrace{\left[\frac{z}{\theta^{*}}+\alpha(\pi Y-l) h\left(\theta^{*}\right)\right]}_{\theta^{*} k\left(\theta^{*}\right)}-(1-\alpha) \frac{z}{\theta^{*}}\} \\
\theta^{*} k\left(\theta^{*}\right) & =\frac{\alpha}{\beta}(r+1-\pi) v+\alpha[c+(1-\pi) K]+(1-\alpha)\left(\theta_{\theta^{*}}\right.
\end{aligned}
$$

It follows that:

$$
\begin{aligned}
& \theta^{*} k\left(\theta^{*}\right)-A=\frac{\alpha}{\beta}(r+1-\pi) v+\alpha[c+(1-\pi) K]+(1-\alpha) \frac{z}{\theta^{*}}-\alpha[c+(r+1-\pi) v+(1-(\mathbb{A}) .5 \mathbb{B} \mathbb{1}) \\
& \theta^{*} k\left(\theta^{*}\right)-A=\alpha\left(\frac{1-\beta}{\beta}\right)(r+1-\pi) v+(1-\alpha) \frac{z}{\theta^{*}} \geq 0 .
\end{aligned}
$$

Thus, $\theta^{*} k\left(\theta^{*}\right)$ is higher than $A$ and $w^{*}$ is increasing in $c, l$ and $K$.

Finally, following the same reasoning with respect to the probability of a successful journey $(\pi)$, we get:

$$
\frac{\partial w^{*}}{\partial \pi}=\frac{1}{h\left(\theta^{*}\right)}\left[\frac{A\left[\beta K+\beta Y h\left(\theta^{*}\right)+v\right]}{\beta \theta^{*} k\left(\theta^{*}\right)}-(v+K)\right] .
$$

From the implicit definition of $\theta^{*}$ (eq. 53), we have:

$$
\beta \theta^{*} k\left(\theta^{*}\right)=\alpha(r+1-\pi) v+\alpha \beta[c+(1-\pi) K]+(1-\alpha) \beta \frac{z}{\theta^{*}} .
$$

Replacing $A$ by its expression, it follows that:

$$
\frac{\partial w^{*}}{\partial \pi}=\frac{1}{\beta \theta^{*} h\left(\theta^{*}\right)^{*} k\left(\theta^{*}\right)}\left[\alpha(1-\beta) v(c-r K)+A \beta Y h\left(\theta^{*}\right)-(1-\alpha) \beta(v+K) \frac{z}{\theta^{*}}\right],
$$

with an unknown sign. 


\section{A.4 Proof of Proposition 6 on $W^{*}$}

Proof. Equation (11) gives the equilibrium intertemporal value of a candidate to migration:

$$
V^{M}\left(\theta^{*}, w^{*}\right)=\frac{z+g\left(\theta^{*}\right)\left(\pi Y-w^{*}\right)}{r+\pi g\left(\theta^{*}\right)} .
$$

Differentiating this equation with respect to $X=c, l$ or $K$, we get:

$$
\begin{aligned}
\frac{\partial V^{M}\left(\theta^{*}, w^{*}\right)}{\partial X} & =\frac{\left[\frac{\partial g\left(\theta^{*}\right)}{\partial X}\left(\pi Y-w^{*}\right)-g\left(\theta^{*}\right) \frac{\partial w^{*}}{\partial X}\right]\left[r+\pi g\left(\theta^{*}\right)\right]-\pi \frac{\partial g\left(\theta^{*}\right)}{\partial X}\left[z+g\left(\theta^{*}\right)\left(\pi Y-w^{*}\right)\right]}{\left[r+\pi g\left(\theta^{*}\right)\right]^{2}} \\
\frac{\partial V^{M}\left(\theta^{*}, w^{*}\right)}{\partial X} & =\frac{\frac{\partial g\left(\theta^{*}\right)}{\partial X} r\left[\pi\left(Y-\frac{z}{r}\right)-w^{*}\right]-g\left(\theta^{*}\right) \frac{\partial w^{*}}{\partial X}\left[r+\pi g\left(\theta^{*}\right)\right]}{\left[r+\pi g\left(\theta^{*}\right)\right]^{2}} .
\end{aligned}
$$

Propositions 2 and 5 state that $\theta^{*}$ and thus $g\left(\theta^{*}\right)$ are decreasing in $X$ and that $w^{*}$ is increasing in $X$. Thus $\frac{\partial V^{M}\left(\theta^{*}, w^{*}\right)}{\partial X} \leq 0$.

Then, from eq. (30), we differentiate $W^{*}$ with respect to $X=c, l$ or $K$ :

$$
\begin{aligned}
& \left.\frac{\partial W^{*}}{\partial X}=\pi \frac{\partial g\left(\theta^{*}\right)}{\partial X}\left[Y-\frac{z}{r}-\frac{w^{*}}{\pi}-V^{M}\left(\theta^{*}, w^{*}\right)\right]-\pi g\left(\theta^{*}\right)\left[\frac{1}{\pi} \frac{\partial w^{*}}{\partial X}+\frac{\partial V^{M}\left(\theta^{*}, w^{*}\right)}{\partial X}\right]+\frac{\partial V^{M}\left(\theta_{(A}^{*} w^{*}\right)}{\partial X}\right) \\
& \frac{\partial W^{*}}{\partial X}=\frac{\partial g\left(\theta^{*}\right)}{\partial X}\left\{\pi\left[\left(Y-\frac{z}{r}\right)-V^{M}\left(\theta^{*}, w^{*}\right)\right]-w^{*}\right\}+\left[1-\pi g\left(\theta^{*}\right)\right] \frac{\partial V^{M}\left(\theta^{*}, w^{*}\right)}{\partial X}-g\left(\theta^{*}\right) \frac{\partial w_{(A}^{*}}{\left.\partial X^{A} .63\right)}
\end{aligned}
$$

The difference $\pi\left[\left(Y-\frac{z}{r}\right)-V^{M}\left(\theta^{*}, w^{*}\right)\right]$ is the expected net surplus of the successful migrant, which, at the equilibrium, should be larger than the smuggling fee if the candidate to migration accepts the smuggling contract. Therefore $\left\{\pi\left[\left(Y-\frac{z}{r}\right)-V^{M}\left(\theta^{*}, w^{*}\right)\right]-w^{*}\right\} \geq 0$ and $\frac{\partial W^{*}}{\partial X} \leq 0$

We follow the same reasoning for $Y$. First, we differentiate $V^{M}$ with respect to $Y$ :

$$
\begin{aligned}
& \frac{\partial V^{M}\left(\theta^{*}, w^{*}\right)}{\partial Y}=\frac{\left[r+\pi g\left(\theta^{*}\right)\right]\left[\frac{\partial g\left(\theta^{*}\right)}{\partial Y}\left(\pi Y-w^{*}\right)+g\left(\theta^{*}\right)\left(\pi-\frac{\partial w^{*}}{\partial Y}\right)\right]-\pi \frac{\partial g\left(\theta^{*}\right)}{\partial Y}\left[z+g\left(\theta^{*}\right)\left(\pi Y-w^{*}\right)\right]}{\left[r+\pi g\left(\theta^{*}\right)\right]^{2}} \\
& \frac{\partial V^{M}\left(\theta^{*}, w^{*}\right)}{\partial Y}=\frac{\frac{\partial g\left(\theta^{*}\right)}{\partial Y} r\left[\pi\left(Y-\frac{z}{r}\right)-w^{*}\right]+g\left(\theta^{*}\right)\left[r+\pi g\left(\theta^{*}\right)\right]\left(\pi-\frac{\partial w^{*}}{\partial Y}\right)}{\left[r+\pi g\left(\theta^{*}\right)\right]^{2}} .
\end{aligned}
$$

Proposition 2 states that $\theta^{*}$ and thus $g\left(\theta^{*}\right)$ are increasing in $Y$. Besides, from eq. (46), (48) 
and (55), we have:

$$
\begin{aligned}
\frac{\partial w^{*}}{\partial Y} & =\frac{A}{\theta^{*} h\left(\theta^{*}\right)} \frac{\partial \theta^{*}}{\partial Y}=\frac{A}{\theta^{*} h\left(\theta^{*}\right)} \frac{\pi h\left(\theta^{*}\right)}{k\left(\theta^{*}\right)} \\
\frac{\partial w^{*}}{\partial Y} & =\pi \frac{A}{\theta^{*} k\left(\theta^{*}\right)} \leq \pi .
\end{aligned}
$$

Since $\left[\pi\left(Y-\frac{z}{r}\right)-w^{*}\right] \geq 0$, then $\frac{\partial V^{M}\left(\theta^{*}, w^{*}\right)}{\partial Y} \geq 0$.

Then, we differentiate $W^{*}$ with respect to $Y$ :

$$
\begin{aligned}
& \frac{\partial W^{*}}{\partial Y}=\pi \frac{\partial g\left(\theta^{*}\right)}{\partial Y}\left[Y-\frac{z}{r}-\frac{w^{*}}{\pi}-V^{M}\left(\theta^{*}, w^{*}\right)\right]+\pi g\left(\theta^{*}\right)\left[1-\frac{1}{\pi} \frac{\partial w\left(\theta^{*}\right)}{\partial Y}-\frac{\partial V^{M}\left(\theta^{*}\right)}{\partial Y}\right]+\frac{\partial V^{M}\left(\theta^{*}\right)}{\partial Y}(\Lambda 8) \\
& \frac{\partial W^{*}}{\partial Y}=\frac{\partial g\left(\theta^{*}\right)}{\partial Y}\left\{\pi\left[\left(Y-\frac{z}{r}\right)-V^{M}\left(\theta^{*}, w^{*}\right)\right]-w^{*}\right\}+\left[1-\pi g\left(\theta^{*}\right)\right] \frac{\partial V^{M}\left(\theta^{*}\right)}{\partial Y}+g\left(\theta^{*}\right)\left[\pi-\frac{\partial w\left(\theta^{*}\right)}{\partial Y} \cdot 6 \rho\right)
\end{aligned}
$$

Since $\left\{\pi\left[\left(Y-\frac{z}{r}\right)-V^{M}\left(\theta^{*}, w^{*}\right)\right]-w^{*}\right\} \geq 0$, we can conclude that $\frac{\partial W^{*}}{\partial Y} \geq 0$.

We follow the same reasoning for $\pi$. First, we differentiate $V^{M}$ with respect to $\pi$ :

$$
\begin{aligned}
& \frac{\partial V^{M}\left(\theta^{*}\right)}{\partial \pi}=\frac{\left[r+\pi g\left(\theta^{*}\right)\right]\left[\frac{\partial g\left(\theta^{*}\right)}{\partial \pi}\left(\pi Y-w^{*}\right)+g\left(\theta^{*}\right)\left(Y-\frac{\partial w\left(\theta^{*}\right)}{\partial \pi}\right)\right]-\left[g\left(\theta^{*}\right)+\pi \frac{\partial g\left(\theta^{*}\right)}{\partial \pi}\right]\left[z+g\left(\theta^{*}\right)\left(\pi Y-w^{*}\right.\right.}{\left[r+\pi g\left(\theta^{*}\right)\right]^{2}} \\
& \frac{\partial V^{M}\left(\theta^{*}\right)}{\partial \pi}=\frac{\frac{\partial g\left(\theta^{*}\right)}{\partial \pi} r\left[\pi\left(Y-\frac{z}{r}\right)-w^{*}\right]+g\left(\theta^{*}\right)\left\{r\left(Y-\frac{z}{r}\right)+g\left(\theta^{*}\right) w^{*}\right\}-g\left(\theta^{*}\right)\left[r+\pi g\left(\theta^{*}\right)\right] \frac{\partial w\left(\theta^{*}\right)}{\partial \pi}}{\left[r+\pi g\left(\theta^{*}\right)\right]^{2}} \\
& \frac{\partial V^{M}\left(\theta^{*}\right)}{\partial \pi}=\frac{\frac{\partial g\left(\theta^{*}\right)}{\partial \pi} r\left[\pi\left(Y-\frac{z}{r}\right)-w^{*}\right]+g\left(\theta^{*}\right)\left[r\left(Y-\frac{z}{r}\right)+g\left(\theta^{*}\right) w^{*}\right]}{\left[r+\pi g\left(\theta^{*}\right)\right]^{2}}-\frac{g\left(\theta^{*}\right)}{r+\pi g\left(\theta^{*}\right)} \frac{\partial w\left(\theta^{*}\right)}{\partial \pi} .
\end{aligned}
$$

Then, from eq. (29), we differentiate $W^{*}$ with respect to $\pi$ :

$$
\begin{aligned}
\frac{\partial W^{*}}{\partial \pi}= & {\left[g\left(\theta^{*}\right)+\pi \frac{\partial g\left(\theta^{*}\right)}{\partial \pi}\right]\left[Y-\frac{z}{r}-V^{M}\left(\theta^{*}, w^{*}\right)\right]-\pi g\left(\theta^{*}\right) \frac{\partial V^{M}\left(\theta^{*}\right)}{\partial \pi}+\frac{\partial V^{M}\left(\theta^{*}\right)}{\partial \pi}-\frac{\partial g\left(\theta^{*}\right)}{\partial \pi} w^{*}-g\left(\theta^{*}\right) \frac{\partial w}{\partial} } \\
\frac{\partial W *}{\partial \pi}= & \frac{\partial g\left(\theta^{*}\right)}{\partial \pi}\left\{\pi\left[\left(Y-\frac{z}{r}\right)-V^{M}\left(\theta^{*}, w^{*}\right)\right]-w^{*}\right\} \\
& +\left[1-\pi g\left(\theta^{*}\right)\right] \frac{\partial V^{M}\left(\theta^{*}\right)}{\partial \pi}+g\left(\theta^{*}\right)\left[Y-\frac{z}{r}-V^{M}\left(\theta^{*}, w^{*}\right)-\frac{\partial w\left(\theta^{*}\right)}{\partial \pi}\right],
\end{aligned}
$$

with an undetermined sign. 


\section{I \\ ESSEC \\ BUSINESS SCHOOL}

ESSEC Business School

3 avenue Bernard-Hirsch

CS 50105 Cergy

95021 Cergy-Pontoise Cedex

France

Tel. +33 (0)134433000

www.essec.edu

\section{ESSEC Executive Education}

CNIT BP 230

92053 Paris-La Défense

France

Tel. +33 (0)1 46924900

www.executive-education.essec.edu

\section{ESSEC Asia-Pacific}

5 Nepal Park

CONTACT

Singapore 139408

RESEARCH CENTER

Tel. +65 68849780

research@essec.edu

\section{www.essec.edu/asia}

ESSEC | CPE Registration number 200511927D

Period of registration: 30 June 2017 - 29 June 2023

Committee of Private Education (CPE) is part of SkillsFuture Singapore (SSG)

\section{ESSEC Africa}

Plage des Nations - Golf City

Route de Kênitra - Sidi Bouknadel (Rabat-Salê)

Morocco

Tel. +212 (0)5 37824000

www.essec.edu 